\title{
Novel Efficient Approach to Connect Raspberry Pi with Laptop
}

\author{
Diksha Singla, Divij Singla
}

\author{
Gyan City Research Lab, Gurgaon, India \\ singla145@gmail.com, singladivij@gmail.com
}

\begin{abstract}
Earlier scientist focus was in harnessing the benefits available in Raspberry pi in order to make any design that is fully controlled by the raspberry pi. There was no any focus on connection between raspberry pi and computer of developer. Our current work is an effort to fill that research gap. Raspberry Pi is the most convenient and efficient method nowadays to do any task. It is the smartest way to connect and interface. Image processing is one of main task done by this small device. As this device is very small it would be an excellent hacking tool.
\end{abstract}

Keyword: Laptop, Raspberry PI, Hardware Hardware Interface, Card Size Computer, Integrated Circuits

\section{Introduction}

The Raspberry Pi is a low cost, credit-card sized computer that plugs into a computer monitor or TV, and uses a standard keyboard and mouse. It is a capable little device that enables people of all ages to explore computing, and to learn how to program in languages like Scratch and Python. It's capable of doing everything you'd expect a desktop computer to do, from browsing the internet and playing high-definition video, to making spreadsheets, word-processing, and playing games. What's more, the Raspberry Pi has the ability to interact with the outside world, and has been used in a wide array of digital maker projects, from music machines and parent detectors to weather stations and tweeting birdhouses with infra-red cameras. Connecting this device with a tv screen will not be that compatible as compared to laptop and it can be used anywhere. In below section, we will describe steps how to connect it with your laptop. First of all we need to install some operating system in our raspberry pi 2. It is recommended to use raspbian . To download this operating system go to raspberry site [4] then you have to select raspbian. In addition to this we need to download some basic softwares Win32 Disk Imager [5], SD Formatter for Windows [6] and 7 zip [7]. In [8], scientist were harnessing the benefits available in Raspberry pi in order to make a robot vehicle that is fully controlled by the raspberry pi. After downloading all these softwares we have to follow these steps:

1.Insert memory card to computer. 
2.Now open sd formatter software, select memory card drive and then click on options> FORMAT TYPE: FULL(erase) and FORMAT SIZE ADJUSTMENT:ON> OK>FORMAT.

3.Now click on downloaded raspbian file and extract it using 7zip. After extracting we will notice a disc image file of 4.Raspbian-. Then open Win32 Disk Imager > select formed disc image > click write. Wait for processing and after its done with $100 \%$ you will see a command of write successful. Your raspberry pi has been successfully booted with raspbian.

\section{How to connect raspberry pi 2 with laptop ?}

Now you need to download some basic softwares e.g. Putty [2], Xming [3], and DHCP server [1],

\section{Novel Methodology Shown as Step By Step Implementation}

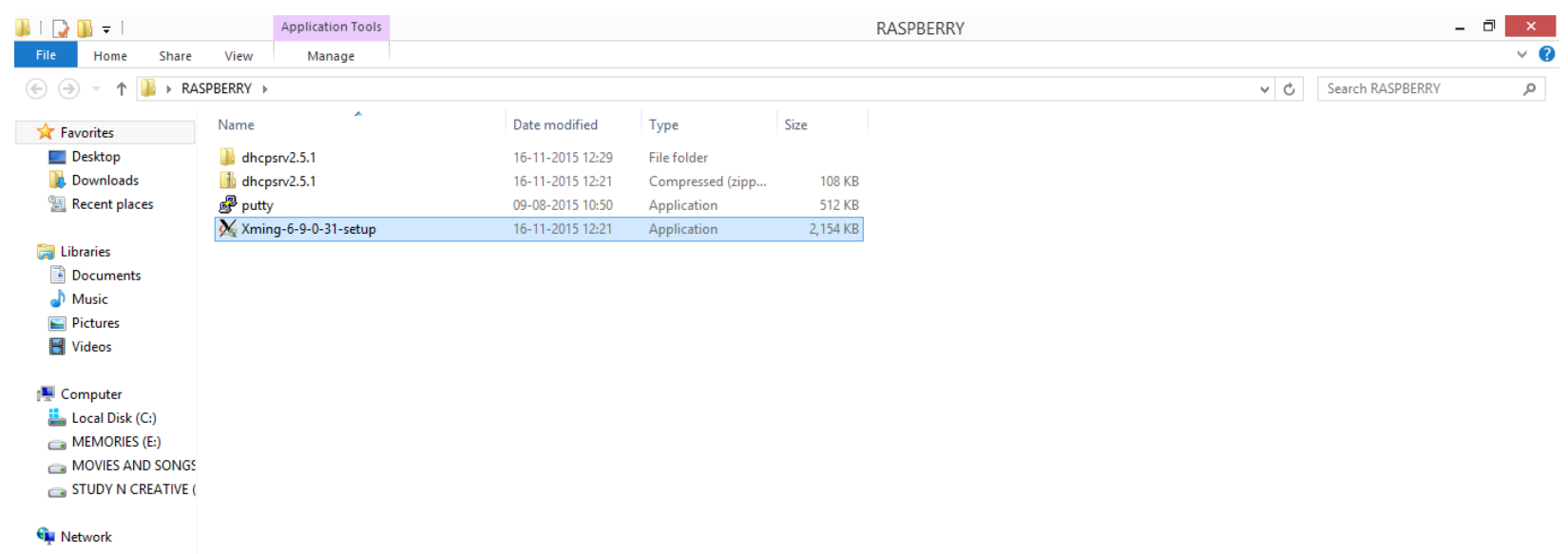

Figure 1: Setup Location of Software that need to be Install

Figure 1 show the location of software and Figure 2-3 deals with the steps related to setup of software. After installing all softwares, we will perform given steps: 
Gyancity Journal of Engineering and Technology,

Vol.2, No.1, pp. 50-61, January 2016

ISSN: 2456-0065 DOI: 10.21058/gjet.2016.2106

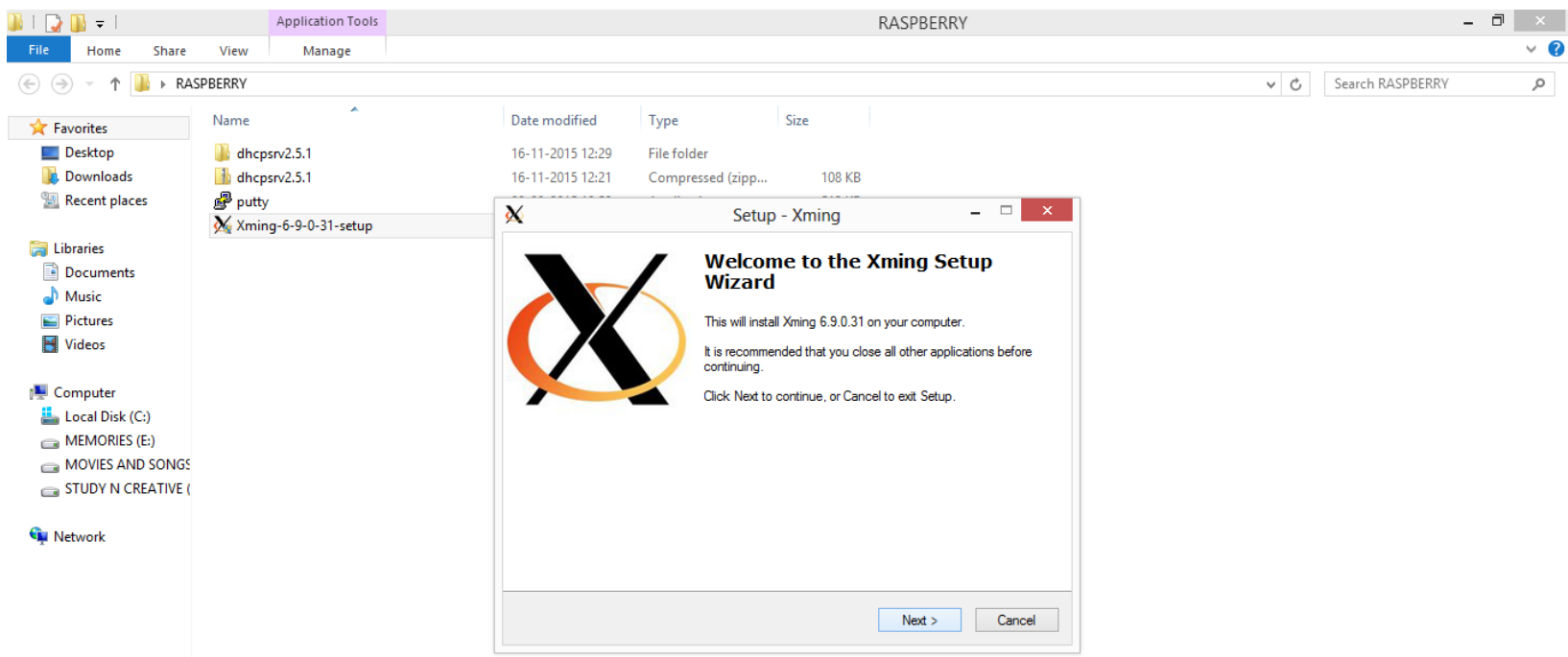

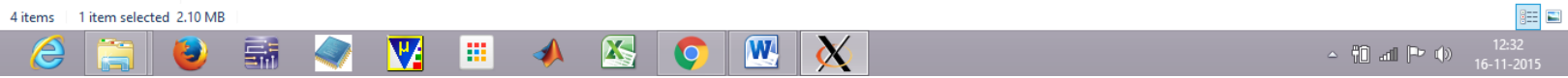

Figure 2: Initial screen of Xming Setup Wizard

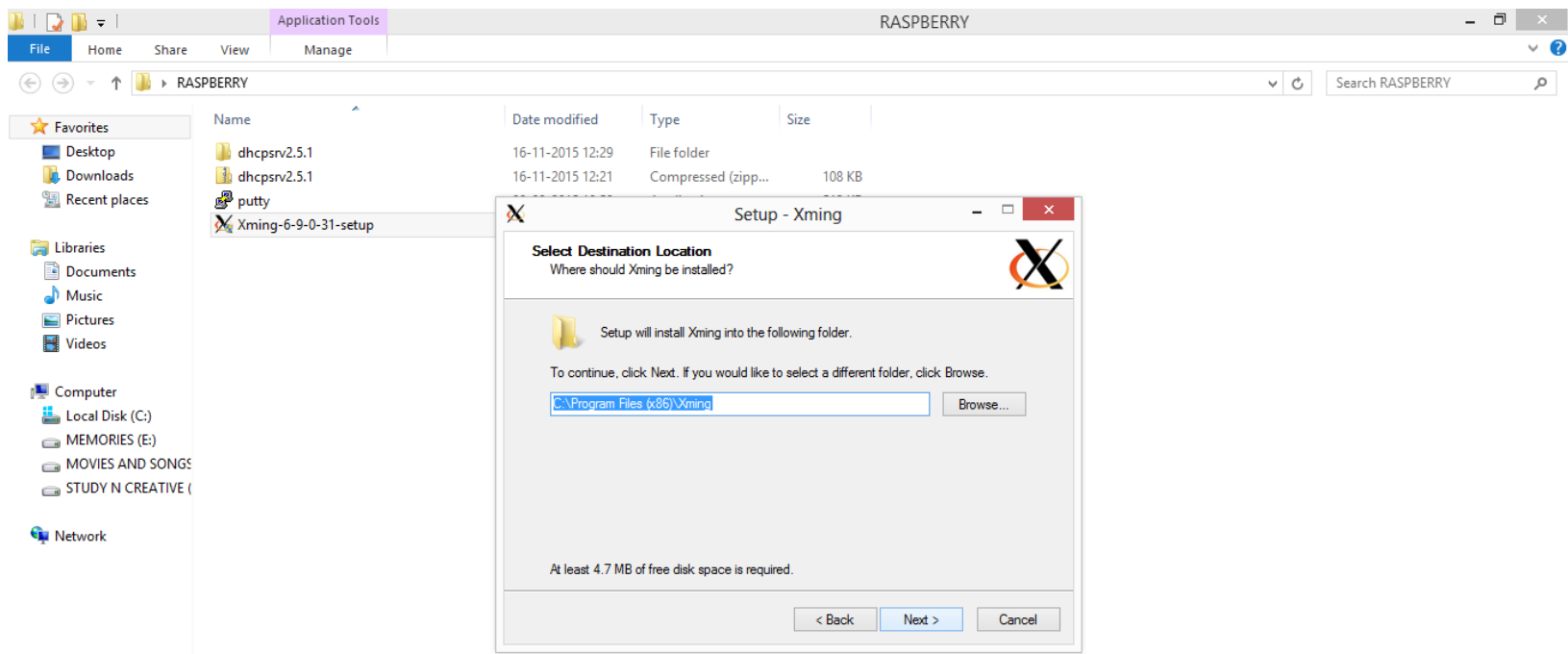

4 4items 1 item selected 2.10 MB

Figure 3: Destination Location of Xming. 
STEP 1.Double click on Xlaunch so that it is minimized to tray.

STEP 2.Then go to Network and Settings

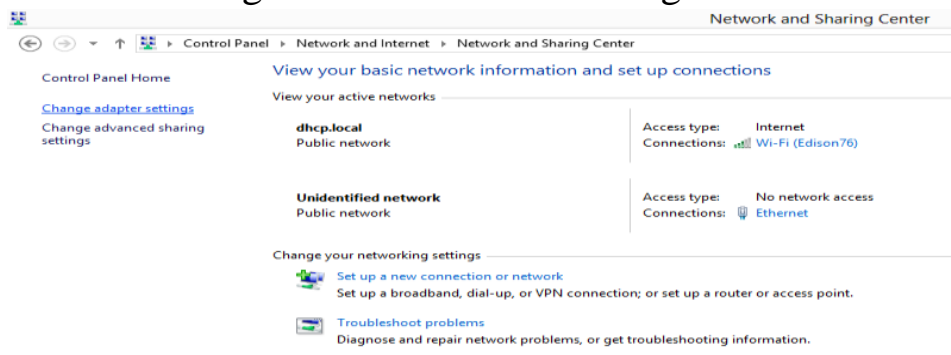

Figure 4: Changing ADAPTER settings

Figure 4 deals with how we can change adapter settings by right click on local area network or going to Ethernet and then to properties.

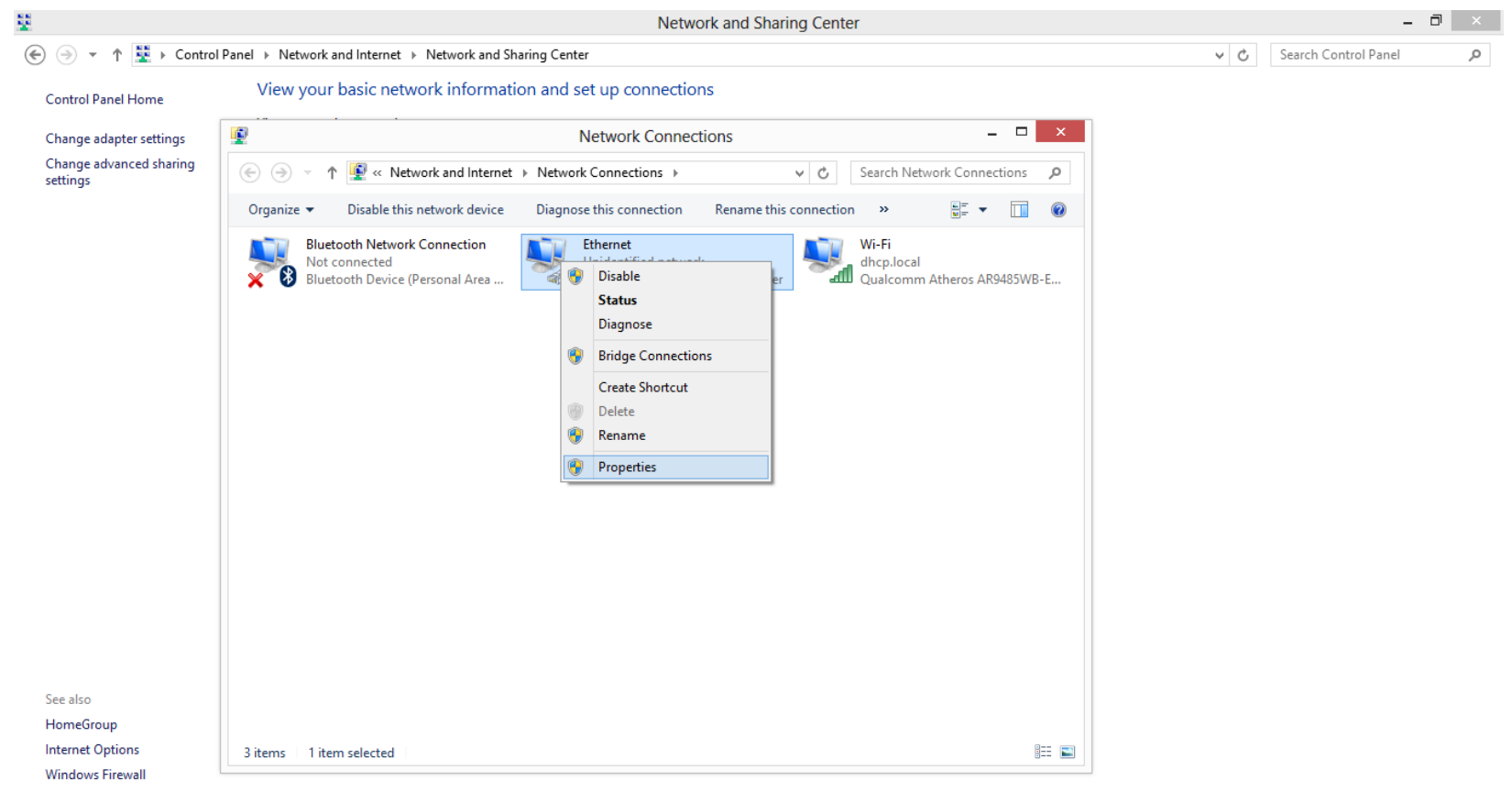

\section{(e)}

Figure 5: Changing ETHERNET properties.

Click on IPv4> 
Gyancity Journal of Engineering and Technology,

Vol.2, No.1, pp. 50-61, January 2016

ISSN: 2456-0065 DOI: 10.21058/gjet.2016.2106

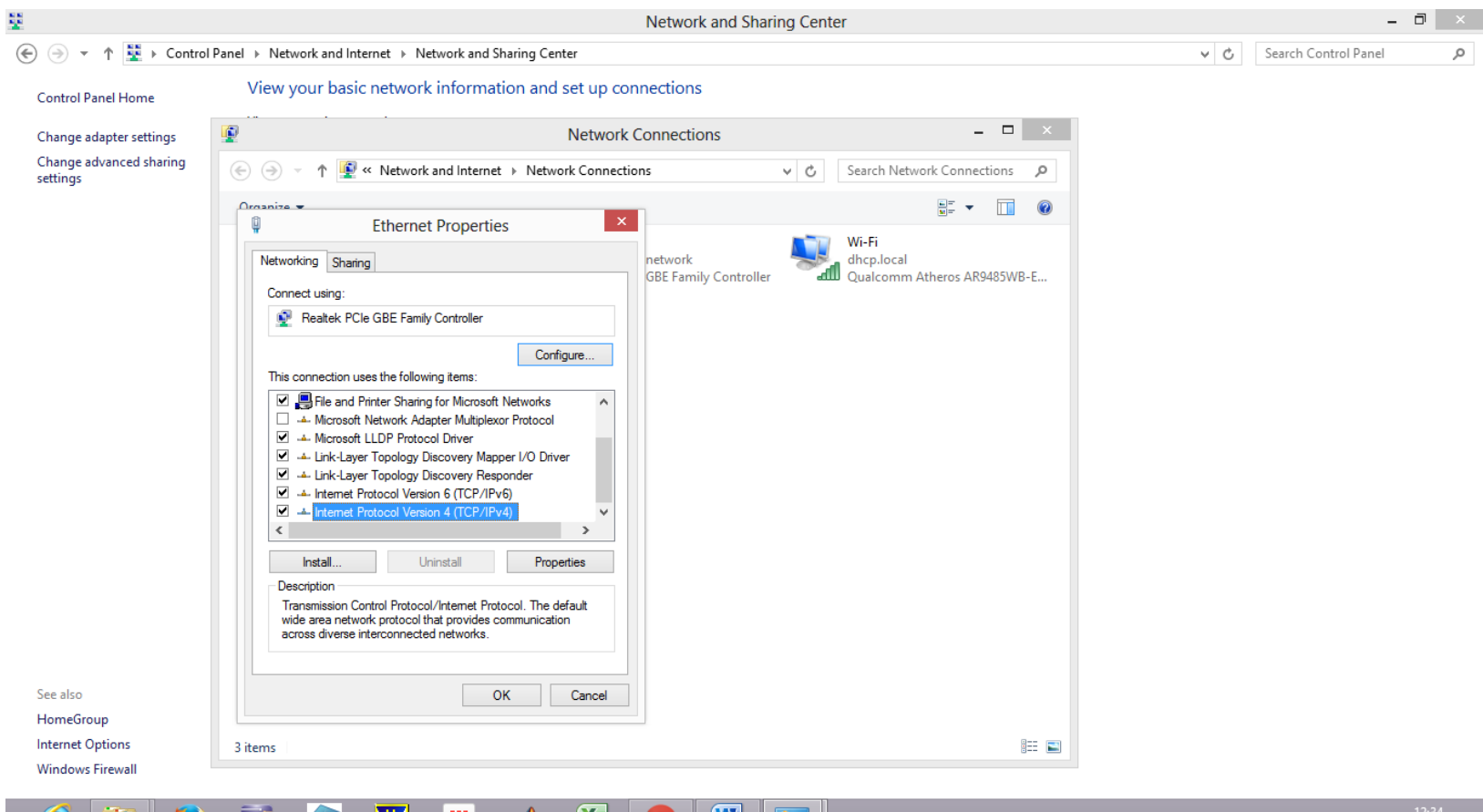

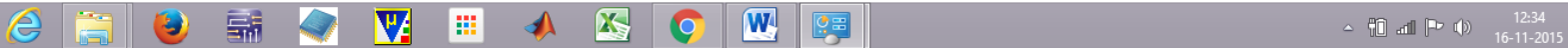

Figure 6: Changing IPv4 setting

<properties>assign ip address as 192.168.2.1>then click on subnet mask you will notice subnet mask will appear automatically>then click ok.

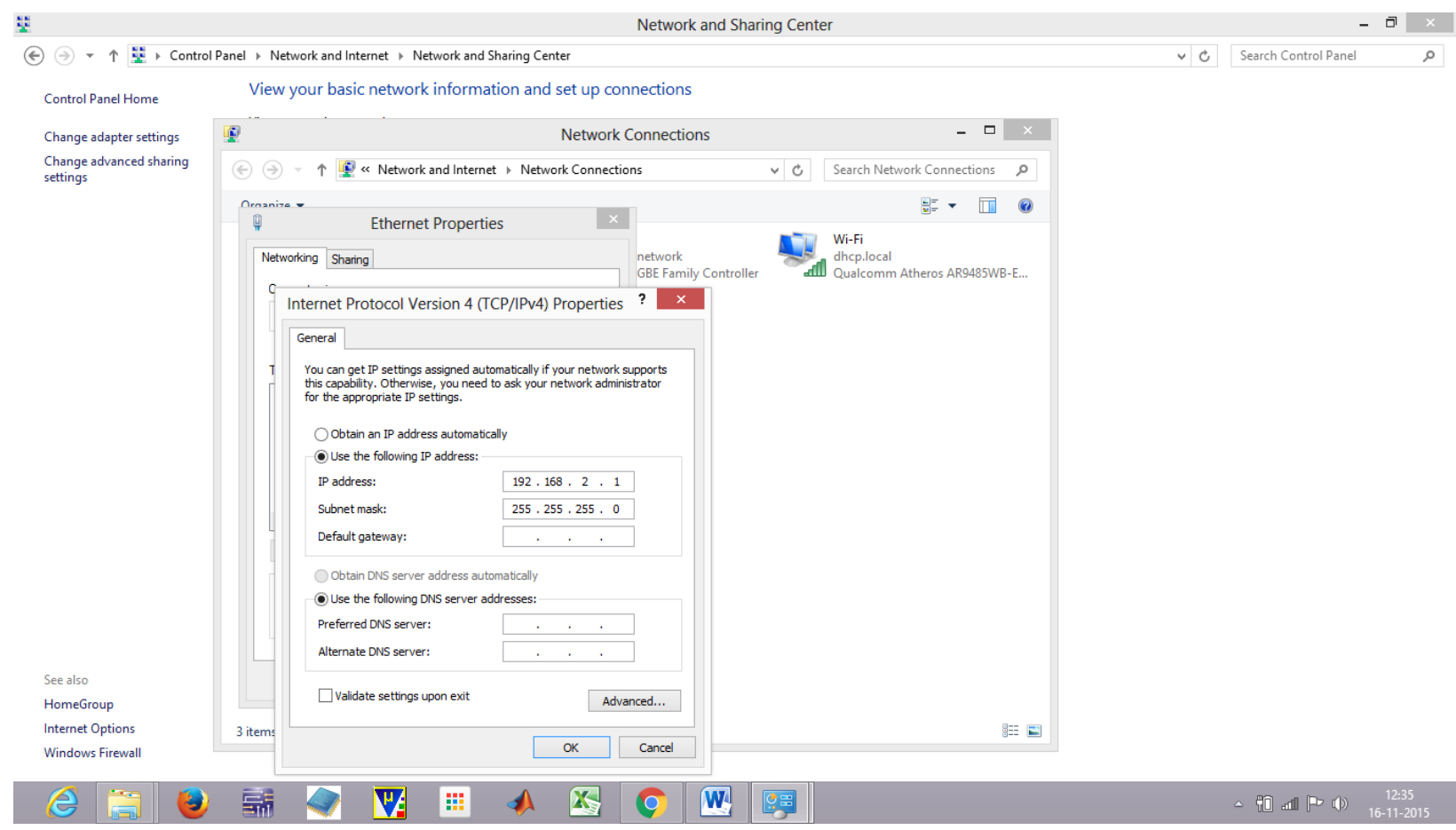

Figure 7: Assigning IP address. 
STEP 3. Now open DHCP SERVER(dhcpwiz) and follow these steps:

Open DHCP folder

>click on dhcpwiz application

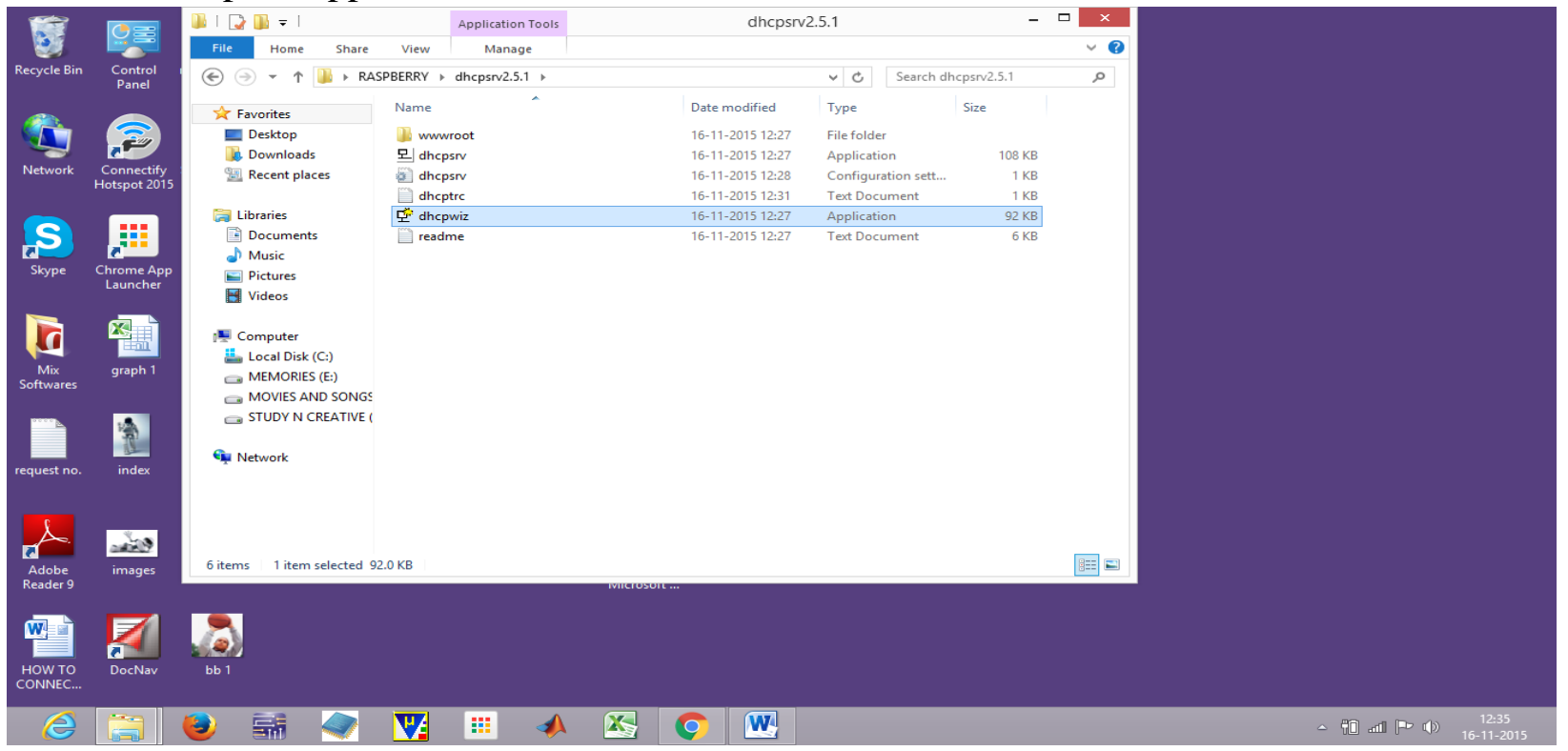

Figure 8: Opening dhcpwiz folder.

This will appear after clicking on dhcpwiz:

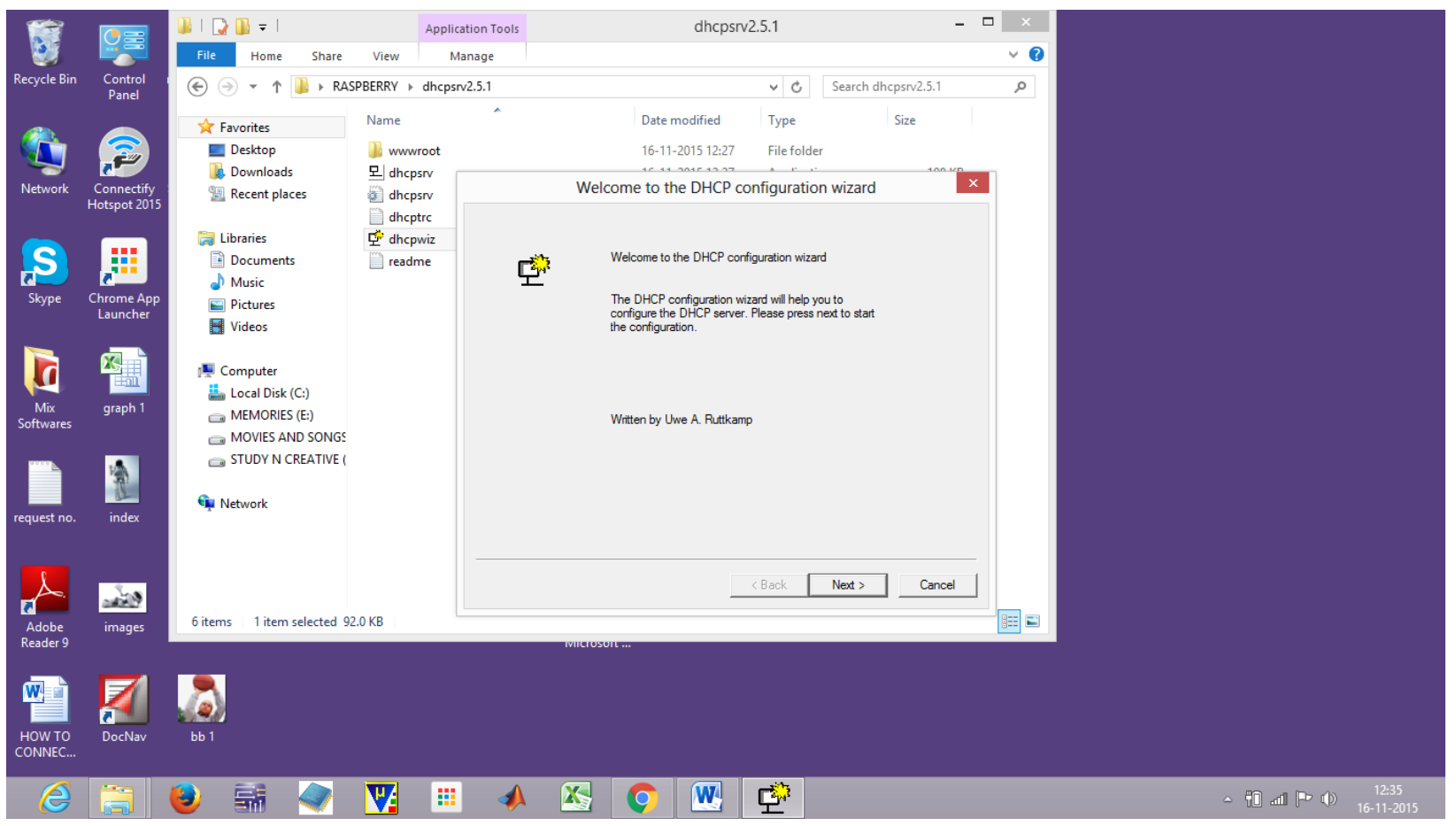

Figure 9: Dhcpwiz initializing screen. 
$>$ select local area network or Ethernet >

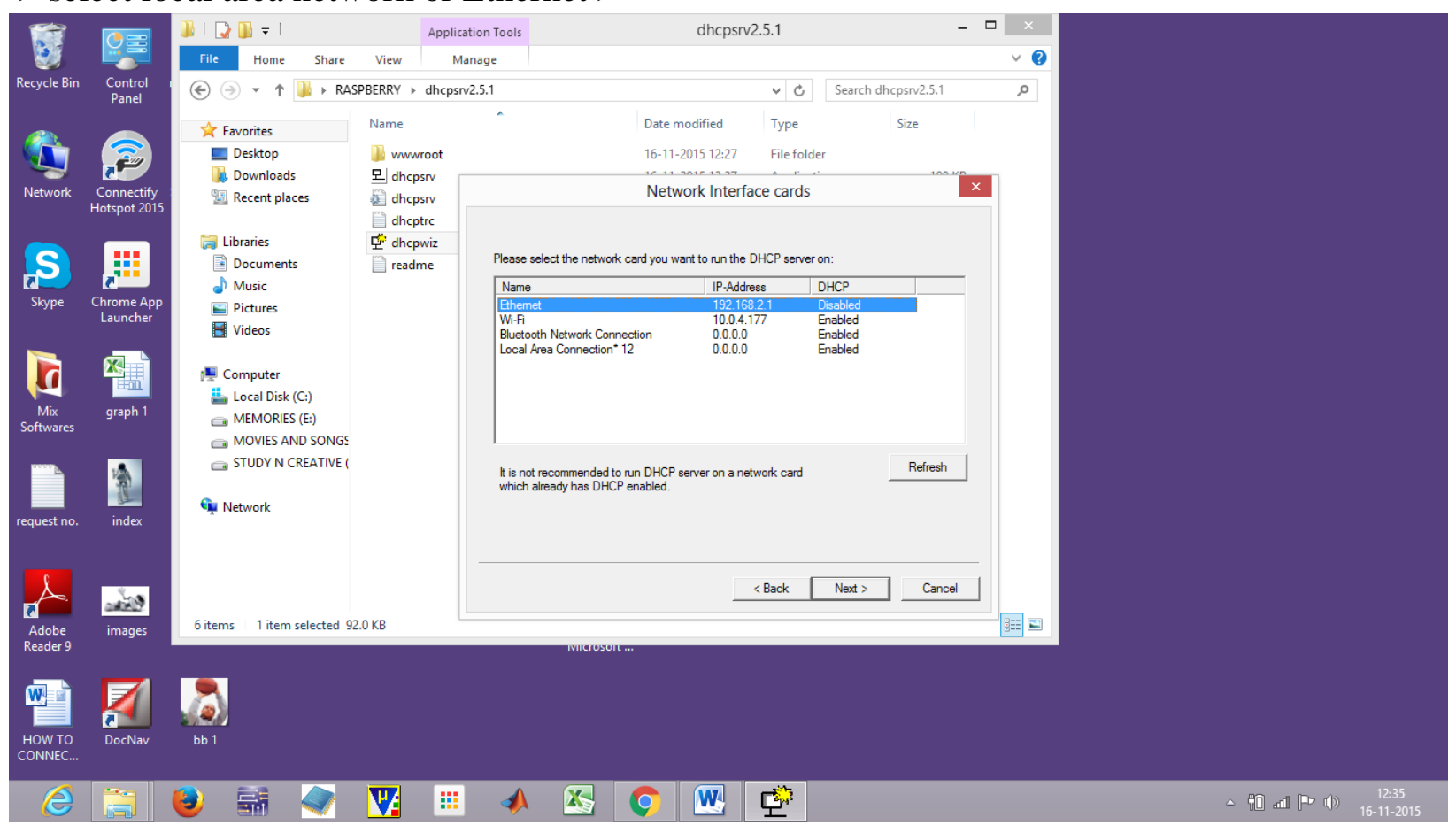

Figure 10: Selecting ETHERNET in dhcpwiz.

Then press next $>$ again next $>$ Now on IP-Root assign 192.168.2.100 - $105>$ then next $>$

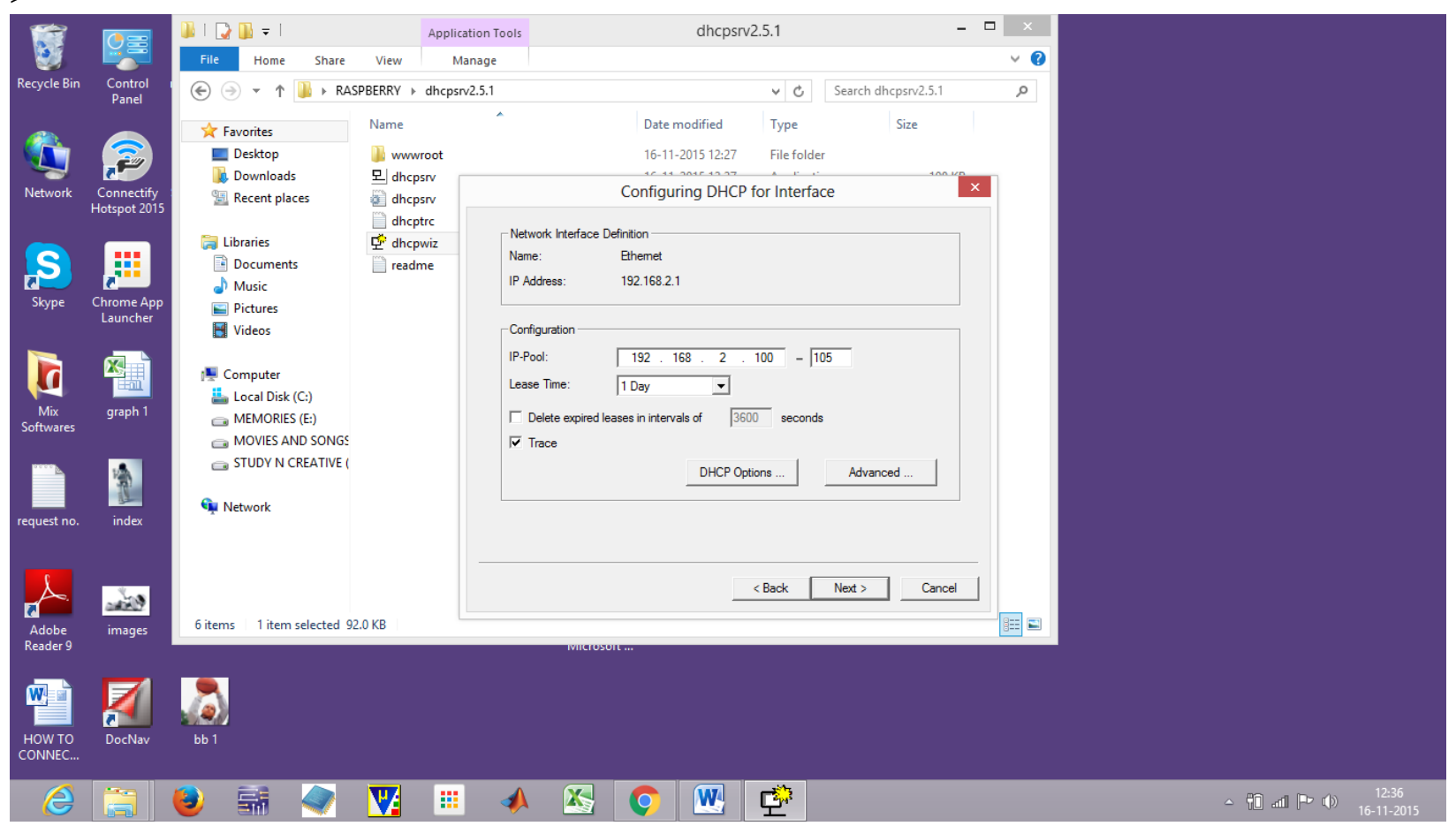

Figure 11: Assigning IP pool 
mark overwrite existing file >

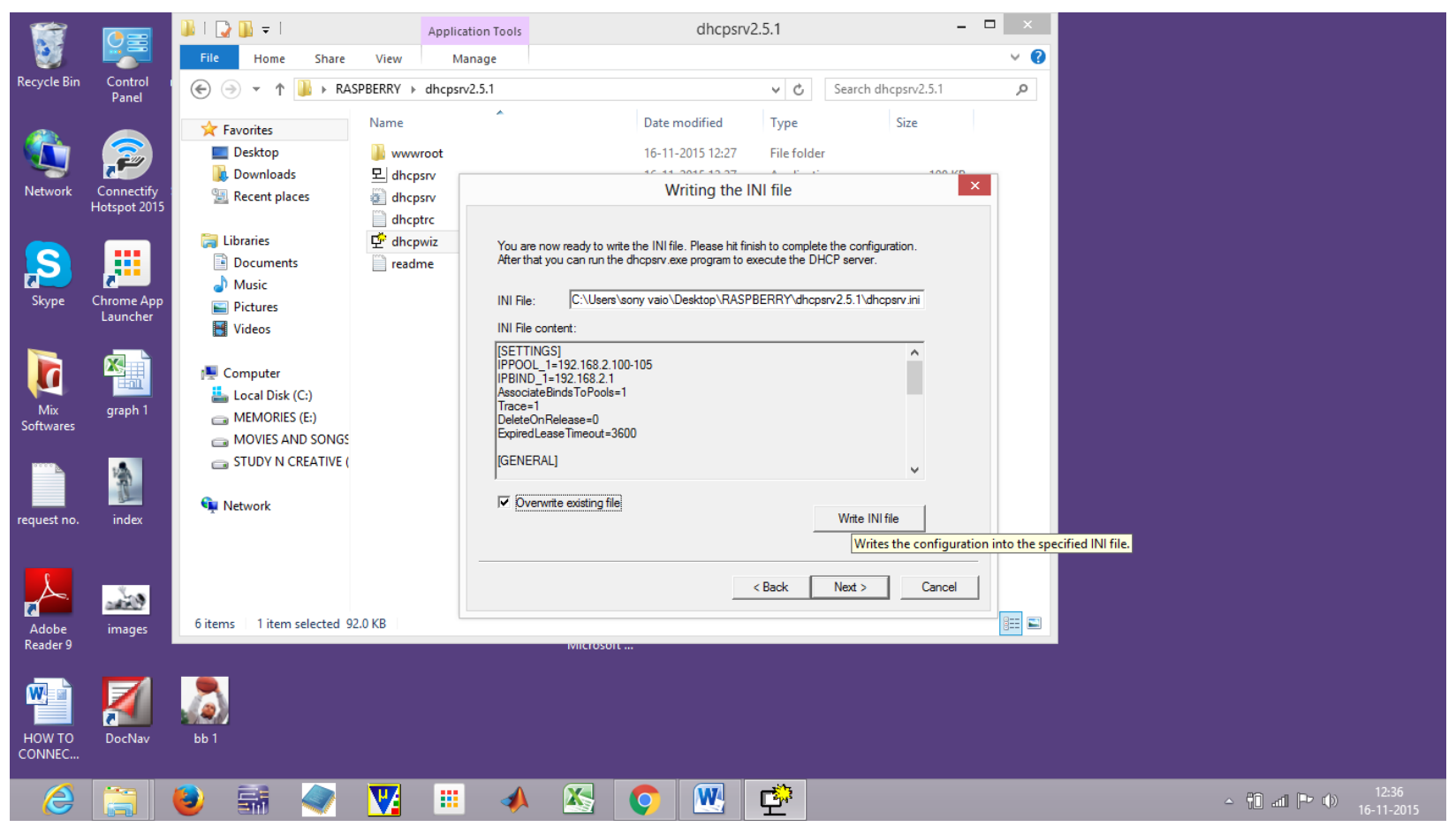

Figure 12: Writing INI file.

Then click write ini file > after you see write successful click next >

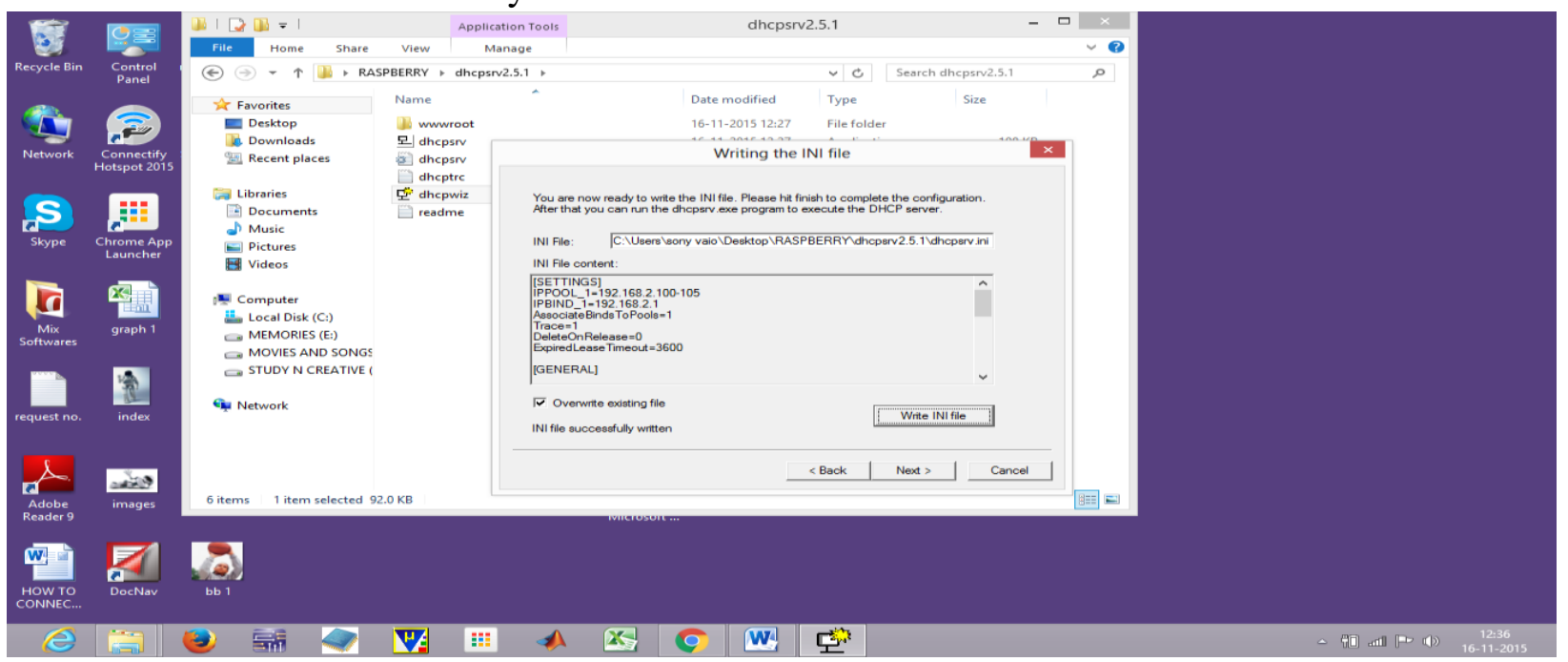

Figure 13: Overwriting INI file.

Now click on configure you will see Status as Running and Configured > mark on run DHCP server then click finish > 




Figure 14: Running DHCP server.

Continue as tray app > yes.

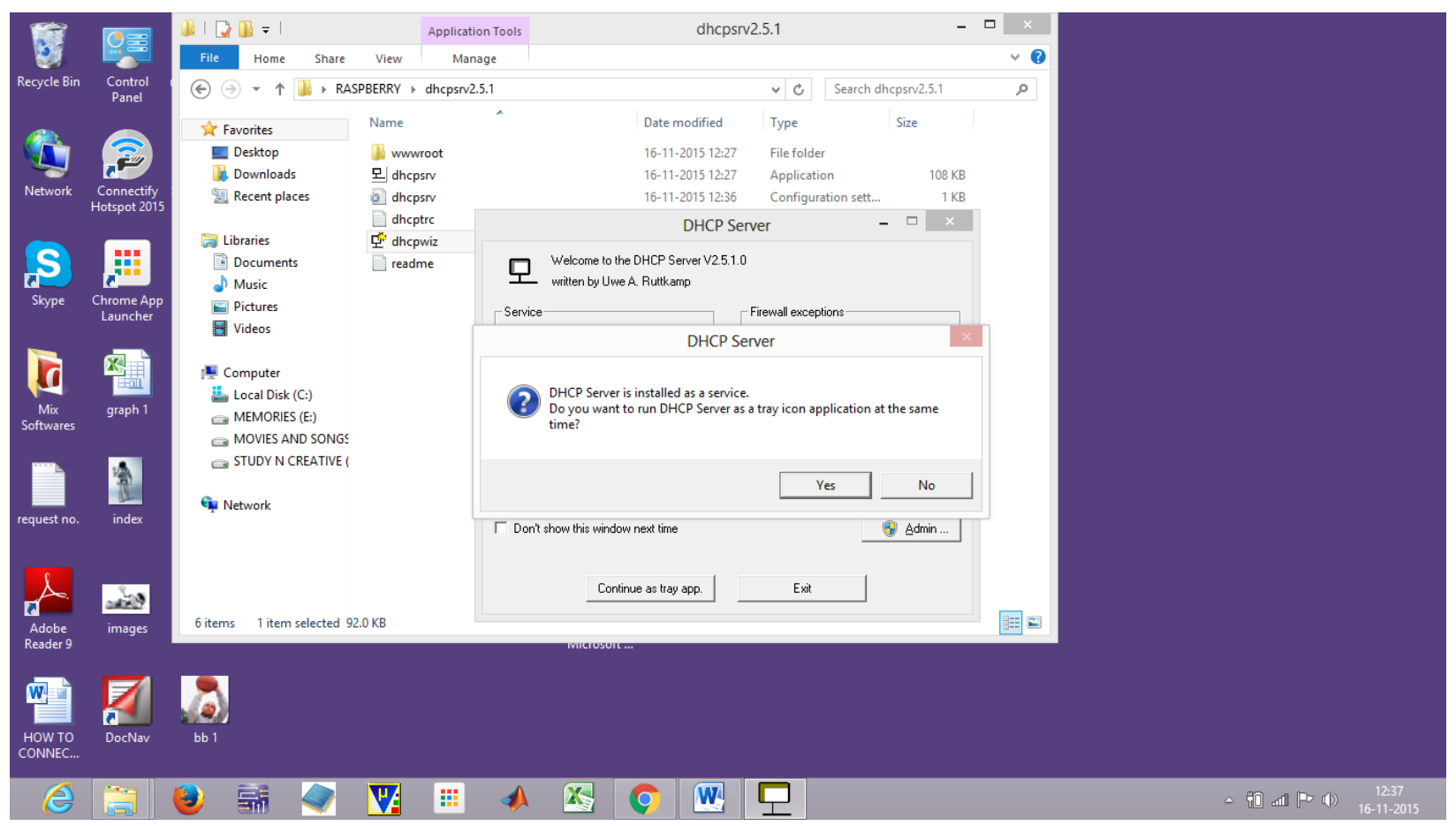

Figure 15: Confirming DHCP as tray icon application.

STEP 4. Now open putty and follow these steps: 
Assign Host name(or IP address) as 192.168.2.100

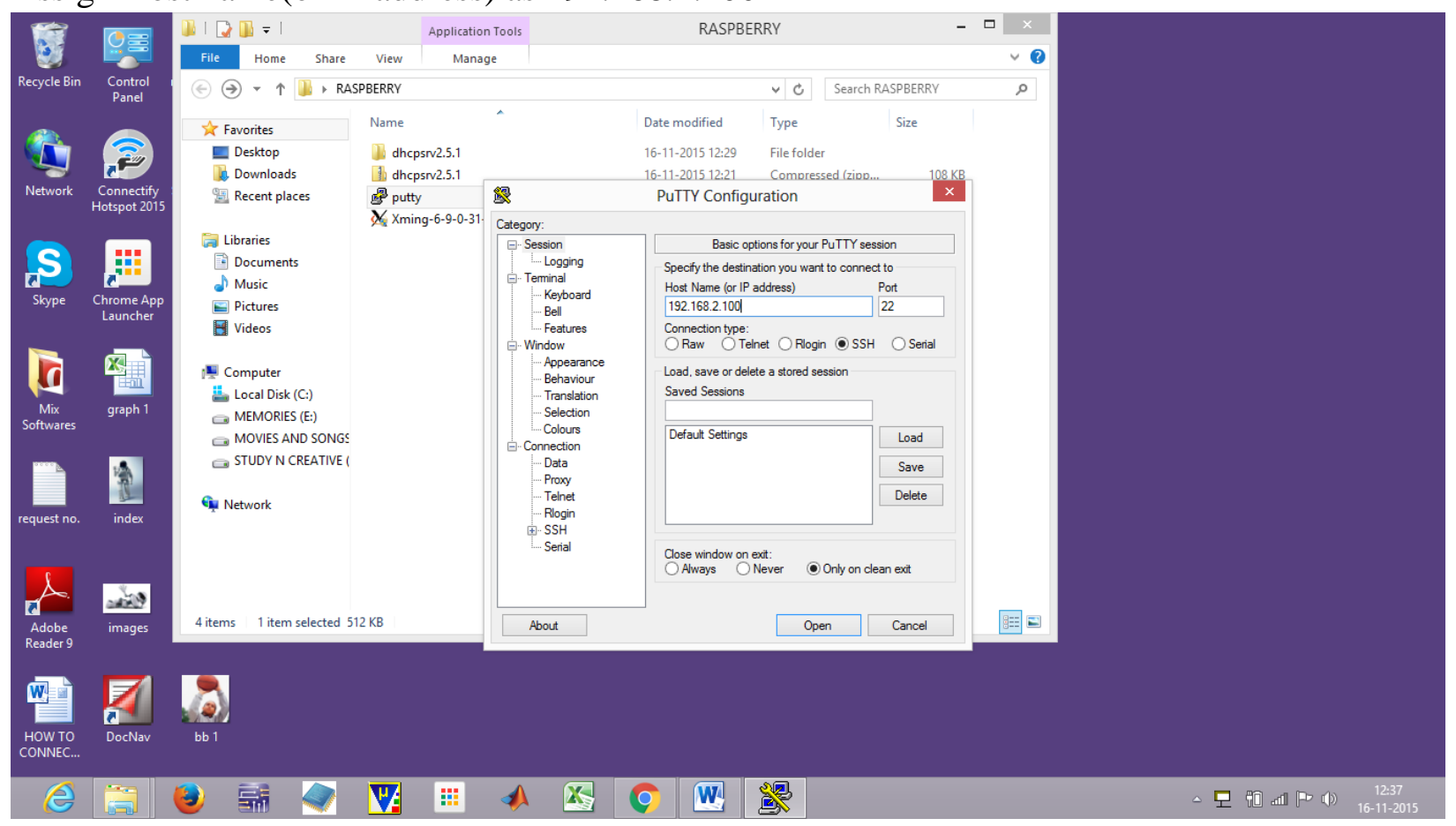

Figure 16: Assigning IP address in putty.

On left side category bar click on X11 > mark Enable X11 forwarding > Open.

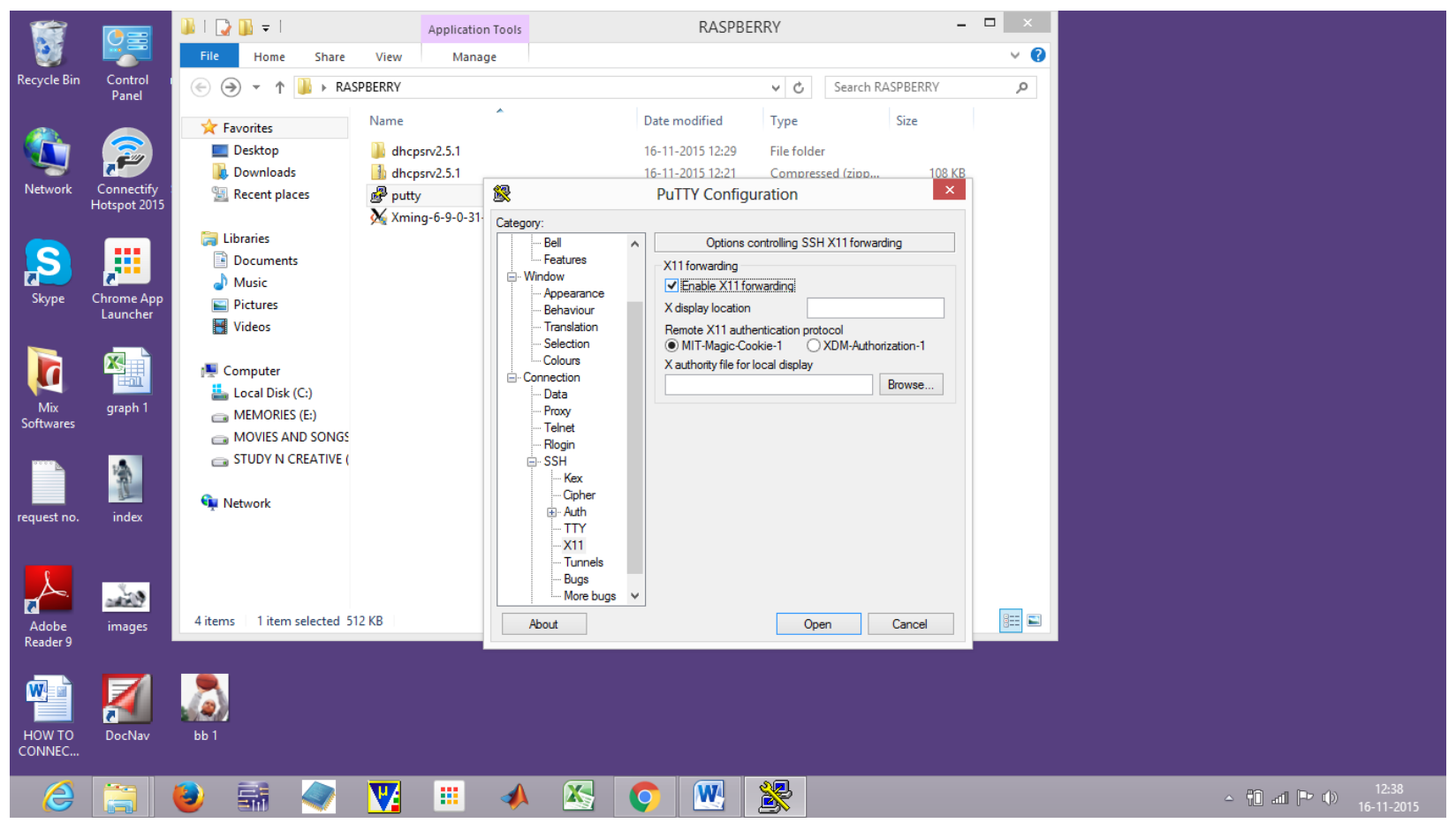

Figure 17: Enabling X11 forwarding. 
It will show a security alert for first time, click on yes.

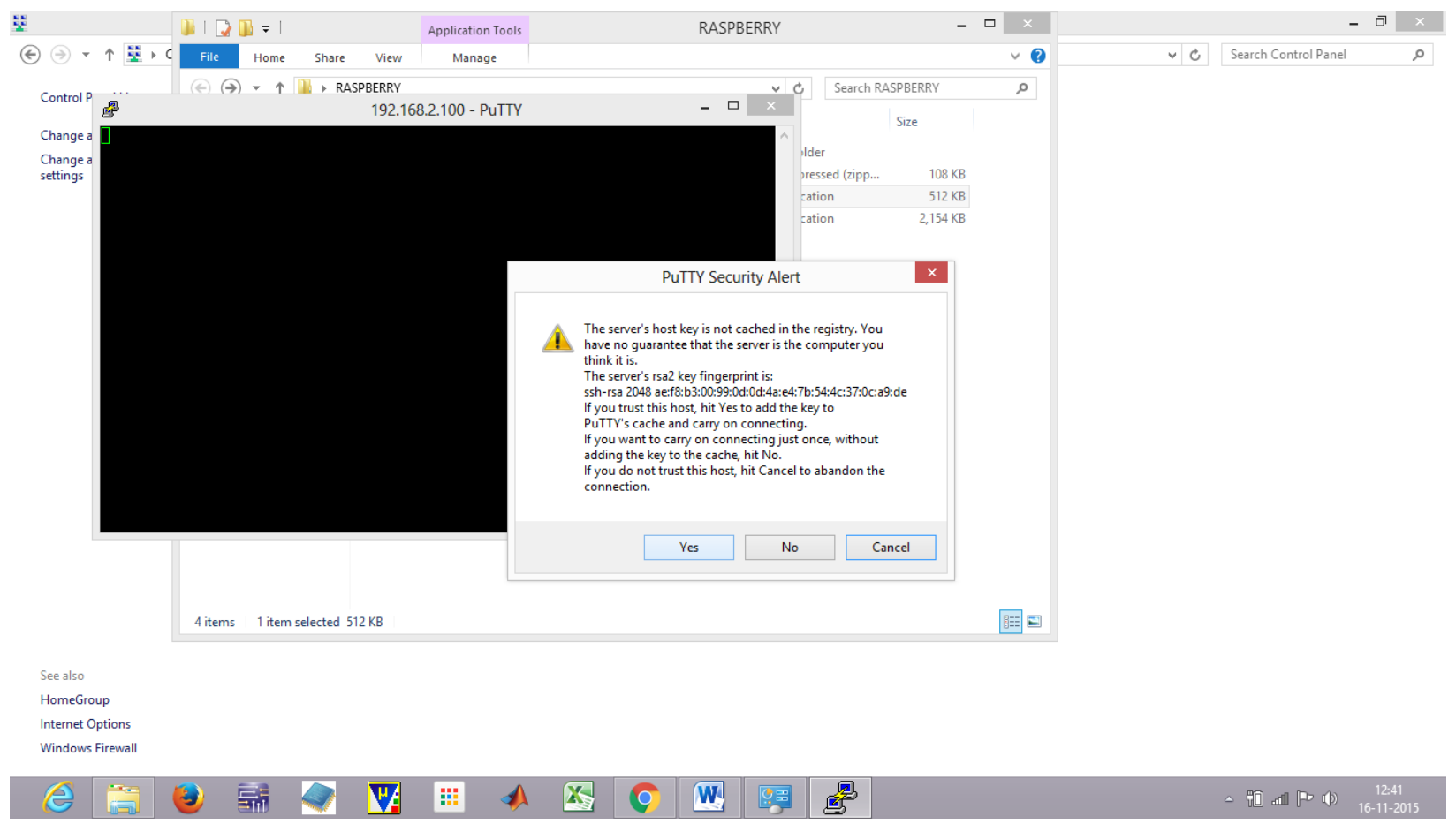

Figure 18:

Now in putty screen enter username as pi and enter, after few seconds it will ask for password : raspberry, enter password and press enter you will not see password so type it carefully, after few seconds you will be all set to play with your raspberry pi 2.

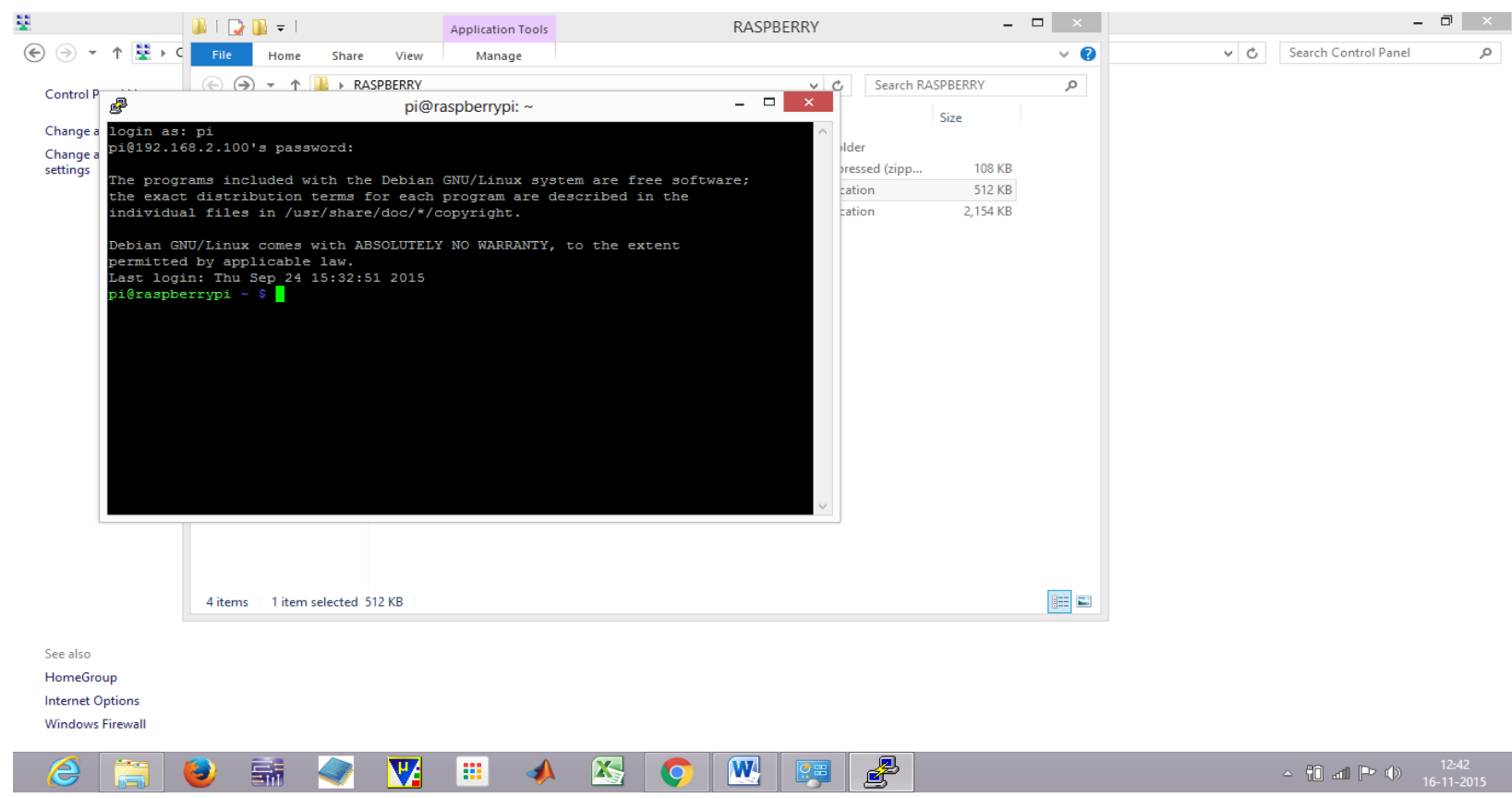


Figure 19: Confirming to carry on with connection.

If it does not work then try unplugging power supply and Ethernet cable and plug it again. Then follow these steps again.

\section{Conclusion}

We successfully connected raspberry pi 2 to our laptop. By using some software we made raspberry pi more compatible to use.

\section{Future Scope}

People working on raspberry pi will no longer have to carry big screens, tv sets, lcd's. They can now simply connect it to their laptop and work anywhere on it. Now as it will be easy to work on raspberry pi new era of innovations will born which will change people's life and make it easier. Now no matter how far are you working you can control appliances through this from anywhere in world.

\section{REFERENCES}

1. DHCP Server Download Link, [[http://www.dhcpserver.de/cms/download/]

2. Putty, [http://www.chiark.greenend.org.uk/ sgtatham/putty/download.html]

3. XMing, [http://sourceforge.net/projects/xming/files/latest/download]

4. Rasberry Pi, [https://www.raspberrypi.org/downloads/raspbian/]

5. Win32 Disk Imager, [http://sourceforge.net/projects/win32diskimager/]

6. SD Formatter, [https://www.sdcard.org/downloads/formatter 4/eula windows/index.html]

7. 7 Zip, [http://www.7-zip.org/download.html]

8. V. Sharma, S. Kaur, R. Mahajan, S. Chawla, T. Khatri, and M. Dhankar, "High Performance Surveillance and Operating Robot with Raspberry Pi", International Journal of Control and Automation, Vol.8. No. 11, 2015. 